International Gender Bias in Nursing Research, 2005-2006:

A Quantitative Content Analysis

Short Title: International Gender Bias in Nursing Research

Denise F. Polit, Ph.D.

President, Humanalysis, Inc., 75 Clinton Street, Saratoga Springs, NY 12866 and Adjunct Professor, Research Centre for Clinical and Community Practice Innovation, Griffith University School of Nursing, Gold Coast, Australia and Cheryl Tatano Beck, DNSc, CNM, FAAN Professor, University of Connecticut School of Nursing, Storrs, CT

Keywords: Gender bias Nursing research

Corresponding author: Denise F. Polit, Humanalysis, Inc., 75 Clinton Street, Saratoga Springs, NY 12866 , dpolit@rocketmail.com (518) 587-3994 
International Gender Bias in Nursing Research 2

\title{
International Gender Bias in Nursing Research, 2005-2006: A Quantitative Content
} Analysis

\begin{abstract}
Aim: This paper reports a study that examined the extent to which nurse researchers internationally disproportionately include females as participants in their research.
\end{abstract}

Background: A bias toward predominantly male samples has been well-documented in medical research, but recently a gender bias favoring women in nursing research has been identified in studies published in four North American journals.

Method: We extracted information about study samples and characteristics of the studies and authors from a consecutive sample of 834 studies published in eight leading Englishlanguage nursing research journals in 2005-2006. The primary analyses involved onesample $t$-tests that tested the null hypothesis that males and females are equally represented as participants in nursing studies. Studies from different countries, in different specialty areas, and with varying author and methodologic characteristics were compared with regard to the key outcome variable, percent of participants who were female.

Results: Overall, $71 \%$ of participants, on average, were female, including $68 \%$ in clientfocused research and 83\% in nurse-focused studies (all $p<.001$ ). Females were significantly overrepresented as participants in client-focused research in almost all specialty areas, particularly in mental health, community health, health promotion, and geriatrics. The bias favoring female participants in client-focused studies was especially strong in the United States and Canada, but was also present in European countries, most Asian countries, and in Australia. Female overrepresentation was persistent, regardless of methodological characteristics (e.g., qualitative versus quantitative), funding source, and most researcher characteristics (e.g., academic rank). Studies with male authors, however, had more sex-balanced samples. The mean percentage female in client-focused studies with 
a female lead author was 70.0, compared to 52.1 for male lead authors.

Conclusion: Nurse researchers not only in North America but around the globe need to pay attention to who will benefit from their research and to whether they are adequately inclusive in studying client groups about which there are knowledge gaps.

Keywords: Nursing research; Gender bias; Sample bias; International comparisons; Professional issues; Document analysis 


\section{What is Already Known About the Topic?}

- There is ample evidence of a bias favoring males as study participants in medical research, but gender bias in nursing research had not been formally studied until recently.

- In an earlier analysis of data from studies published in four leading nursing research journals based in North America in 2005-2006, a bias favoring females as study participants was found.

\section{What This Paper Adds?}

- Findings in this expanded analysis of studies published in eight leading journals suggest that gender bias is pervasive internationally in contemporary nursing research; in virtually all countries, females outnumber males as study participants in client-focused research.

- This international study also identified two problematic areas in nursing research: (1) researchers' failure in many cases to report the sex distribution of their research samples; and (2) the scarcity of analyses examining sex differences in outcomes. 
In the United States, groups of advocates, scientists, and health care leaders drew sharp and critical attention to gender bias in medical research during the 1980s and early 1990s (LaRosa and Pinn, 1993; Woods, 1994). Many public policy changes occurred as a result of the evidence that women were absent or severely underrepresented in major clinical trials funded by the U.S. National Institutes of Health (NIH). Although early evaluations suggested that NIH had been slow in implementing new inclusionary policies, more recent studies suggest that NIH's efforts to reduce gender inequities in health research have led to improvements (U.S. General Accounting Office, 2000). Yet, studies continue to monitor the inclusion of women in medical research, and have found the need for ongoing vigilance and progress (e.g., Geller et al., 2006; Murthy et al., 2004).

Concern about gender bias in medical and epidemiologic research is not restricted to the United States. Over the past two decades, scholarly articles about gender bias favoring males in health care research have been written by clinicians and academics throughout the world, particularly in Europe. Documentation and criticism of gender bias have been expressed, for example, by scholars in the United Kingdom (Bartlett et al., 2005; Doyal, 2001; Holdcroft, 2007), Germany (Fuchs and Maschewsky-Schneider, 2003; Jahn, 2005), Sweden (Hammarström, 2003; Risberg et al., 2006; Söderström, 2001), Ireland (Buckley et al., 2007), and Spain (Ruiz-Cantero et al., 2007).

Within the nursing community, concern about gender bias or discrimination is typically voiced in regard to the recruitment and retention of men in the profession, and the potential of “reverse discrimination” (Anthony, 2004). Evans (2004) noted that, despite the fact that men have worked as nurses for centuries, the history of nursing in most countries has been a history of women's accomplishments and has helped to perpetuate "the ideological designation of nursing as women’s work” (p. 321). Most nurses are, in fact, women. In the United States, for example, only 6 percent of registered nurses are men (U. 
S. Department of Health \& Human Services, 2008). In the United Kingdom, the percentage of male registered nurses is a somewhat higher (10\%, Buchan, 2008), but nevertheless women appear to be in the majority in the profession in most countries. For example, 95\% of the members of Sigma Theta Tau International are women (Sigma Theta Tau, 2008).

The suspicion of gender bias in nursing research was expressed by Dallas and Burton (2004) in their discussion of health disparities and the potential contribution that nurse researchers could make by including more minority males in their studies. They noted that "nursing research has traditionally limited its focus to the health issues of women and children” (p.78). Their speculation of gender bias was recently corroborated in a study that analyzed data from studies published in four non-specialty nursing research journals based in the United States, which found evidence of a bias favoring women as study participants (Polit and Beck, 2008). In the 259 studies in the analysis, $75.3 \%$ of the study participants, on average, were female. The significant bias favoring female participants persisted regardless of most characteristics of the study methods, participants, and researchers.

To the extent that gender bias in nursing research exists, it raises concerns not only about inequities or injustices. Gender bias calls into question the quality of the base of nursing research evidence, and it is this base from which nurses are increasingly expected to practice. If nurses are basing their clinical decisions primarily on studies of women, there is reason to be cautious about generalizing the findings to broader client populations.

A related issue that has been raised within the context of gender sensitivity concerns the lack of information in many studies regarding whether results from mixed-sex samples apply to both males and females. Holdcroft (2007) recently called for nurse researchers to establish gender-specific evidence-based practice, echoing a similar call in 
medicine for understanding the effects of gender on health (Doyal, 2001). This requires an effort among researchers to analyze their data for sex differences in outcomes, an effort that has been infrequently made in medical studies (Geller et al., 2006; Johnson et al., 2003). We found no empirical information in the literature about the extent to which nurse researchers analyze their data for sex differences.

\section{Purpose}

The present study extended our earlier analysis by examining whether gender bias favoring females in nursing research is an international phenomenon. The hypothesis was that a disproportionate number of study participants in nursing studies is female, regardless of country. This study also replicated the earlier analysis by examining the degree to which any gender bias is consistent across researcher, participant, and study characteristics in an international mix of studies.

In this paper, we use the term gender bias as it has been used in the literature on bias within medical research-that is, by looking at proportionate participant representation (e.g., LaRosa and Pinn, 1993; Risberg et al., 2006). Gender bias is thus analogous to a sampling bias - an under- or over-representation of a population segment. Thus, an important distinction in our analysis is whether the focus of the research was on clients or nurses. Among studies that focus on nurses or nursing students, it was fully expected that females would predominate as study participants, because nurses are disproportionately female. Gender bias in nurse-focused studies might be suspected if, for example, the average percentage of females was substantially over $90 \%$, or, in the opposite direction, substantially under $90 \%$. Unfortunately, the absence of specific information about the percentage of female nurses from one study population to another would make inferences about bias in nursing studies speculative.

Thus, most of our analyses focus on studies in which clients were the study 
participants. Given that the population of humans requiring health and nursing care is roughly equal in terms of the two sexes, a bias in nursing research might be inferred if, on average, one or the other sex was systematically underrepresented across nursing studies that focus on client populations.

In this paper, we also examined the extent to which nurse researchers undertake analyses that examine sex differences in key outcomes when both males and females are in the study sample.

\section{METHOD}

\section{Sample}

A consecutive sample of journal articles published in eight English-language nursing research journals in the years 2005 and 2006 comprised the base sample. Journals were selected if they: (1) were non-specialty (generalist) research journals that published research on the full spectrum of nursing investigations; (2) had a strong standing within nursing, which we operationalized by including only journals whose impact factor was .99 or higher in 2006; and (3) were English-language journals. Using these criteria, the four journals used in our initial study (Nursing Research, Qualitative Health Research, Research in Nursing \& Health, and Western Journal of Nursing Research) were supplemented with four journals that have greater representation of European, Australian, and Asian researchers: International Journal of Nursing Studies, Journal of Advanced Nursing, Journal of Clinical Nursing ,and Journal of Nursing Scholarship. Although Qualitative Health Research is not exclusively devoted to nursing research, the editor and many authors are nurse researchers, and we sought an adequate sample of qualitative nursing studies from North America. Excluding editorials, the initial selection yielded a sample of 1,594 articles from 164 journal issues.

Because of our interest in analyzing the sex distribution of study participants in 
relation to other study characteristics, we focused on primary research in which individual people were the unit of analysis. Consequently, some of these 1,594 articles were excluded from the sample, for one or more of the following reasons: the article was a review article, meta-analysis, or concept analysis $(N=159)$; the article was an essay rather than a study ( $N$ = 195); the report involved a study in which individual people were not the unit of analysis, such as studies of institutions or animals $(N=47)$; and the research team did not include any registered nurses $(N=181)$. Of the 1,594 original articles, 553 articles were excluded for one of more of these reasons. Of the 1,041 remaining studies, however, the researchers failed to provide information about the sex distribution of study participants in another 205 articles. Thus, analyses in this paper are based primarily on the remaining 836 studies.

In preparing for the original study, we did a pilot test with a random sample of 40 studies from the four journals and assessed our sample size needs. Even with a sample of only 40 studies, a significant tendency to overrepresent women was detected. Thus, the final sample of 836 studies in these analyses yielded substantial statistical power for the main hypothesis, and adequate power to test inter-country variations and variations relating to most characteristics of the studies and the researchers.

Because of low statistical power when the number of studies in a subset was small (e.g., studies from Greece or Jordan), we present results only when there were at least 10 studies in the subset. This decision forced us, in our analyses of country differences, to either eliminate articles from countries with 9 or fewer studies, or to group countries based on geographic proximity. So, for example, we included two New Zealand studies with Australian studies. We created some multi-national groupings with, such as "other European,” rather than delete studies from Denmark, Germany, Greece, Italy, Malta, Spain, and Switzerland entirely. We combined studies from Belgium and the Netherlands rather than putting them in the "other European” category. Unfortunately, even after making these 
sub-optimal grouping decisions, some countries were omitted from cross-country comparisons. For example, there were only 5 African studies from three countries. Thus, regrettably, no African, South American, or Central American studies were included in country-specific analyses. Results from broad country groupings and from countries with a small number of studies should be considered tentative.

\section{Variables and Data Extraction}

Full papers for each study in our sample were retrieved and reviewed. Relevant information from each article was extracted, coded, and entered onto a coding protocol. This section describes variables for which data were extracted.

Sex of participants. The primary “outcome” variable for this study was the sex distribution of study participants. We extracted the number of females and number of males in the study samples, and used this information to create several indicators, the most important of which was the percentage female in each study.

Other characteristics of participants. We extracted information about the participants’ age and created four age groups: children (ages 0 to 18), young adults (ages 19-25), adults (ages 26-59), and seniors (ages 60 and older). We also coded the "role” of the primary study participants: patients or clients; informal caregivers; parents; nurses; other health care staff; and combinations of participants, such as nurses and patients.

Country. We coded a country for each article based on the first author's institutional affiliation. One reason for not using participants’ country of residence was that some studies were conducted in multiple countries. In the vast majority of studies (93\%), the first author's institution was located in the same country as all participants.

Sex of the authors. The first author's sex was coded, and we also coded whether any of the other authors were male. We coded authors' sex directly whenever the names were easily identifiable. When there was ambiguity, we took steps to identify sex for lead 
authors. Primarily, we did an Internet search to identify the authors' sex-typically by going to the websites of the institutions with which authors were affiliated. We also asked a colleague from China to assist us with the names of Asian authors. We were unable to code 30 studies (2\%) for first author's sex, and 95 studies (11\%) for other authors' sex. These studies were excluded only in the analyses that examined the relationship between authors’ sex and percentage female among participants.

Specialty Area. The nursing specialty area of each study was coded, with up to two codes allowed to encompass studies focusing on topics that cut across disciplinary boundaries, such as a study of elderly patients with cancer. Two broad classes were established: (1) studies that were client-focused, which are sometimes called exogenous or outward-looking studies (Cecil, et al., 2006; Traynor et al., 2001); and (2) studies that were nursing-focused, or endogenous/inward-looking. Within the former broad category, the specialty areas were: pediatrics; geriatrics; obstetrics and gynecology; oncology; cardiopulmonary; critical care; other medical/surgical; psychiatry/mental health; community health; health promotion; and transcultural. Specialty areas within the nursingfocused category included nursing administration; nursing education; and clinical nursing practice. Studies coded in the "clinical nursing practice” category were studies that focused on such issues as clinical decision making, nurses’ workloads, nurses’ research utilization, and so on.

Funding. We coded whether or not the authors acknowledged funding of any type that helped to support the research.

Methodologic characteristics. Studies were coded as either quantitative, qualitative, or mixed method, depending on the type of data used in the analyses reported. Quantitative and mixed method studies were further classified as experimental (i.e., with an intervention) or nonexperimental/observational. Qualitative studies were categorized 
according to research tradition, such as grounded theory, phenomenologic, or ethnographic. We also coded the type of data collected (e.g., self-report, observation), and whether the focus of the research was methodologic, such as instrument development papers. Finally, for quantitative studies that included participants of both sexes, we coded whether the researchers had undertaken analyses that addressed whether findings could be generalized to males and females. Studies were coded as having a sex-differentiated analysis if the researchers presented subgroup results for males and females, if they used sex as an independent variable in regression analysis, or if they specifically noted that sex differences in outcomes were or were not significant.

\section{Intercoder Reliability}

The journal articles were independently coded by the two authors. After we completed coding the 1,594 articles in the primary sample, 100 studies were selected at random to be coded by both researchers. Interrater agreement on the 48 coded variables ranged from $84 \%$ to $100 \%$. The median agreement across 48 variables was $90 \%$. To correct for the possibility of chance agreement, we computed a kappa statistic for dichotomously coded variables (e.g., whether or not the specialty area was oncology). Kappa values for these variables ranged from .86 to 1.00 .

\section{Analyses}

Two types of analyses were undertaken in this paper. One-sample $t$-tests were used to test the null hypothesis that the distribution of men and women in a sample were equal, and 95\% confidence intervals around the mean percentage female were computed. If the lower limit of the $95 \%$ CI was less than $50.0 \%$, the null hypothesis was retained. We computed 95\% CIs around mean percentage female for all subgroups of studies, such as studies from different countries and in different specialty areas.

The second type of analyses involved comparing differences in mean percentage 
female among subgroups of studies. For example, we tested the null hypothesis that all countries have the same percentage female participants using analysis of variance.

Because males and females are approximately proportionately represented in client populations but not in nursing populations, the majority of our analyses relating to possible gender bias in the distribution of study participants are based on client-focused studies.

\section{RESULTS}

A total of 628,724 people from 37 different countries were the study participants in the 1,041 studies in the full sample. As noted, however, not all reports provided information about participants’ sex: overall, $19.7 \%$ of studies lacked participant sex information. Table 1 shows the rate of including sex distribution information, by country of the lead author. Only countries with at least 10 studies in the full sample are individually shown in the table, and others are grouped by geographic region. The percentage of studies that had information about number of male and female participants and could thus be used in the analyses on gender bias ranged from a low of 54.2\% (Ireland) to $100.0 \%$ (Turkey). Differences among countries in providing this demographic information were highly significant $\left(\chi^{2}=110.3, p<.001\right)$.

Of the 541,851 study participants for whom sex was known, 133,825 were male (24.7\%), and 408,026 were female (75.3\%). Within studies, the percentage female ranged from $0 \%$ to $100 \%$, with a mean percentage female of 71.0 . The $95 \%$ confidence interval around this mean percentage was 69.2 to 72.8 (one sample $t=22.96, d f=835, p<.001$ ). Females outnumbered males in $75 \%$ of the studies, whereas males outnumbered females in only $21 \%$ of the studies. There were all-female samples in $26 \%$ of the studies, compared to $2 \%$ that had all-male samples. Thus, there continued to be support for the hypothesis that a disproportionate percentage of study participants in nursing studies is female.

\section{Gender Bias by Specialty Area and Participant Role}


Table 2 presents information about the sex distribution of the studies in our sample by specialty area of the study. The table includes specialty areas within the two previously described broad categories: client-focused and nursing-focused. Table 2 shows (column 5) that in every specialty area, with the single exception of cardiopulmonary, the mean percentage female was greater than 50.0, and studies in all specialties more often had allfemale samples than all-male samples. The disproportionate representation of females was statistically significant $(p<.001)$ for all client-focused specialties combined (mean percentage female $=67.6$ ). In only two specific client-focused specialties (cardiopulmonary and critical care) did the lower limit of the confidence interval around the mean percentage fall below 50.0.

As expected, female overrepresentation was also significant for the three specialty areas within the broad nursing-focused categories. Yet, for all three specialty areas, the mean percentage female was less than 85.0, ranging from 81.5 for studies in nursing administration to 84.4 in nursing education. These percentages suggest that male nurses are well represented and perhaps overrepresented in studies of nurses themselves, although it would be difficult to estimate the extent or even existence of such a bias without knowing population values.

Findings from the specialty category analysis are consistent with analyses that considered the role of participants (not shown in tables). The mean percentage female ranged from 65.8 for studies whose participants were clients or patients, to 88.0 for those whose participants were nurses. The mean percentage female was 70.0 or higher for participants who were informal caregivers, parents, or health care staff other than nurses, as well as for combinations of participant roles. All were statistically significant-that is, the lower limit of the 95\% CI was greater than 50.0, regardless of the participants' category.

Thus, it would seem that nurse researchers favor females as study participants, 
regardless of topic and regardless of what type of person is participating in the study.

\section{Gender Bias by Country}

A central purpose of this extended research was to explore whether gender bias would be observed in countries besides the United States. Table 3 presents information about the percentage female by country, for all studies and also for client-focused studies only. Countries for which there were fewer than 10 studies with sex distribution information (e.g., Belgium) were combined into a broader geographic category. Caution should be exercised, however, in interpreting the results in these aggregated categories, as there was considerable intra-country variation. As previously noted, the analyses shown were based on the country of the lead author, not the country of residence of study participants. This decision reflects our assumption that it is likely to be cultural forces affecting researchers' decisions on what topics to study and whom to invite as study participants that is influencing the key outcome variable in this research. The results are nearly identical, however, when the analyses focus on the country of residence of study participants (not shown in tables).

When all studies for which there was sex information were considered, the mean percentage female of study participants was greater than 50.0 in every country, and was significantly greater than 50.0 for all countries except Turkey. Of greater interest in terms of gender bias, however, is that the mean percentage female was greater than 50.0 in all countries even when only client-focused studies were considered. The lower limit of the 95\% CI failed to be greater than 50.0\% for only three countries, Belgium/Netherlands, Hong Kong/China, and Turkey. Despite widespread overrepresentation of females as study participants, differences among the countries were statistically significant, both for clientfocused studies $(F=2.22, d f=14,624, p=.006)$ and for all studies $(F=2.42, d f=14$, 821, $p=.002$ ). For client-focused studies, gender bias appears to be greatest in the United 
States $($ mean percentage $=72.7)$ and Canada (75.6). Female overrepresentation was least pronounced in several Asian countries, especially in Hong Kong/China, where the mean percentage female was 56.3.

\section{Gender Bias and Authors' Sex}

In our earlier paper, based on studies primarily undertaken in North America (Polit and Beck, 2008), we found that gender bias was fairly persistent, but a factor that affected male-female participation was the authors' sex, especially that of the first author. The results for this expanded analysis, shown in Table 4 for client-focused studies only, are similar to what we found in our initial study: when the first author was male, the mean percentage female was close to 50.0, and the 95\% CI fell below that mark (45.3). The mean percentage female among papers with female first authors was 70.0. The difference in mean percentage female between men and women first authors was highly significant $(t=$ 5.35, $d f=612, p<.001)$.

The bottom panel of Table 4 shows client-focused studies categorized by number of authors and their sex. As this table shows, there were 84 studies authored by a single woman, compared to only 6 studies authored by one man. We have broken our "rule" to present results only when there are at least 10 studies in a subgroup because the results are interesting for their comparative value-and also because they illustrate the problematic lack of precision when there are so few studies in a subset. Client-focused studies conducted by a single female researcher had an especially high mean percentage of female participants (78.2), while those conducted by a single man had an especially low mean percentage female (39.6). However, the range for the 95\% CI for the six male-only papers was over 75 percentage points, making it risky to put any faith in the overall mean percentage of 39.6. Nevertheless, the inclusion of at least one male in multiple-authored papers was also associated with reduced overrepresentation of female clients as study 
participants, and so the overall pattern suggests that researchers' sex is a strong factor affecting the sex composition of study samples $(F=9.60, d f=3$. 555. $p<.001)$.

\section{Gender Bias and Other Factors}

In our earlier paper, we found that evidence of gender bias was fairly consistent regardless of most characteristics of the study methods, authors, and participants. For the most part, our results in this expanded analysis replicate our earlier findings, with a few notable exceptions. In this section, we report results for client-focused studies exclusively; the results are not shown in tables. In terms of participant characteristics, the mean percentage female was greater than 50.0 for participants in all four age groups (children, young adults, adults, and seniors), but the value was not significant for studies involving children (53.0, 95\% CI = 45.1, 60.8). Overrepresentation of females was especially pronounced in studies of young adults (mean percentage female $=80.3$ ).

With regard to study methods, the mean percentage female in client-focused studies was significantly greater than 50.0 for qualitative and quantitative studies; experimental and nonexperimental studies; qualitative studies in every tradition (e.g., grounded theory, phenomenology, and so on); substantive and methodologic research; and studies using selfreports, observation, physiologic methods, records, or multiple means of data collection. Subgroups of studies based on methodological characteristics had similar levels of female overrepresentation, with one exception: qualitative studies had a significantly higher mean percentage of females (72.8) than quantitative studies (64.6) $(t=3.48, d f=611, p<.001)$.

In terms of funding, both funded and unfunded client-focused studies had significant female overrepresentation. The mean percentage female for funded studies (69.1) was significantly higher than that for unfunded studies (64.0) $(t=2.25, d f=634, p=$ .025). This pattern could reflect the fact that U.S. and Canadian studies, where evidence of gender bias was most pronounced, were significantly more likely than studies in other 
countries to have had funding $\left(\chi^{2}=73.5, d f=1, p<.001\right)$.

\section{Sex-Specific Analyses}

Overall, $30.8 \%$ of the quantitative client-focused studies with mixed-sex samples $(N$ = 341 studies) reported analyses on sex differences in outcomes. Researchers in the United Kingdom were least likely to have analyzed for sex differences (20.0\% of relevant studies), whereas researchers in Korea were especially likely to have done so (57.1\% of studies). Both the United States and Australia were exactly at the overall percentage of $30.8 \%$ of studies. Country differences in undertaking sex-specific analyses was significant $\left(\chi^{2}=\right.$ 18.79, $d f=8, p=.02)$.

\section{DISCUSSION}

The findings suggest that nurse researchers, as a group, focus more often on women's health than on men's health; this was found to be the case across most specialty areas, and not simply in the area of gynecology and obstetrics. Gender bias appears to be fairly pervasive internationally in contemporary nursing research, cutting across not only specialties but also research methodologies and client populations.

We have used the term gender bias because decisions about what to study and whom to include in nursing studies reflect choices made by nurse researchers. It is possible that in some client-focused studies a higher rate of females than males results from a higher rate of cooperation among female than male participants. Yet, this could not account for the fact that a full $29 \%$ of all client-focused studies had all-female samples (compared to only 3\% with all-male samples). Even when studies in the obstetrics/gynecologic specialty area are excluded, 21\% of client-focused studies had all-female samples. When males are not even invited to participate, this must reflect researchers', and not participants', decisions.

Gender, which is a social and not a biological construction, encompasses 
expectations and norms about behavior, choices, roles, and interests (Risman, 2004).

Gender bias in nursing research may reflect greater interest in women's health on the part of the predominantly female cadre of nurse researchers. This interpretation is consistent with the finding that gender bias was found primarily in studies with a female lead author. Gender bias in nursing research may also reflect the expectations, encouragement, and enthusiasms of mentors and colleagues regarding certain research topics. The forces affecting nurse researchers' selection of research problems would be an interesting topic for future research, and might lend itself well to in-depth qualitative inquiry.

In their paper on gender bias in epidemiological research, Ruiz-Cantero et al. (2007) warned about "the biased production of new knowledge” (p.46). Nurse researchers need to heed these warnings, because a primary consequence of gender bias in research concerns the validity of the findings. In an environment that stresses the importance of basing practice on evidence, external validity and the generalizability of research are key issues that concern the issue of the groups and subgroups to which the evidence can meaningfully be applied.

This study also brought to the forefront two additional problem areas in nursing research: (1) researchers' failure to report the number of males and females in their samples; and (2) the scarcity of analyses on sex differences in study outcomes. More than 200 studies from the original sample could not be included in our study because the researchers failed to report the sex distribution of study participants. Researchers from Ireland and the UK were particularly remiss in this regard: information about the sex of study participants was absent in about $45 \%$ of their studies. Basic demographic information about the sample such as sex, age and —in many countries—race/ethnicity—should be standard features of the report. In terms of sex-specific analyses, only about one-third of quantitative studies that are client-focused and that include both males and females 
reported analyses of sex differences in outcomes. Both of these problem areas have implications for evidence-based practice.

Nurse researchers not only in North America but around the globe have a responsibility to provide new knowledge for gender specific evidence-based practice (Holdcroft, 2007). By collecting and reporting gender data, gaps in the knowledge base can be filled by nurse researchers so that evidence-based practice guidelines are gender sensitive.

\section{Study Limitations}

This study was successful in developing a large and international sample of recently-published nursing studies, but the degree to which these studies are representative of contemporary nursing research cannot be determined. It is likely that the quality of these studies is fairly high, perhaps higher than the average nursing study, given the high impact factors of the selected journals. Nevertheless, there are likely to be different forces operating in different countries that lead researchers to submit articles to the selected eight journals. In particular, studies by researchers from non-English-speaking countries are likely to be a biased subset of research being conducted in those countries, and the direction and nature of such biases are not known.

Despite the limitations and ambiguity with regard to sample bias, this study's positive features are worth noting. In particular, we had a large sample size with considerable statistical power. To generate a large sample of studies, we used two full years of publications, selected eight different journals (164 separate journal issues), and drew a consecutive sample of all papers, not a subsample of papers, published in those issues. We retrieved, read, and extracted data from each full article. Despite potential biases in the sample of studies, there is no a priori reason to suspect that gender bias would be greater or less in journals not included in our sample. Our findings offer a baseline against which 
future efforts to document nurse researchers’ selection of balanced samples of participants can be evaluated.

Hopefully, our findings will be given thoughtful consideration by nurse leaders and nurse researchers around the globe. Just as medical researchers-who in the 1970s and 1980s were primarily men—needed to have their consciousness raised about the importance of including women in their studies, so too must nurse researchers pay attention to the needs of the populations they serve.

\section{Author Contributions}

Both authors contributed to the conceptualization of the project, its design, and the writing of this paper. Both also shared the data extraction/data coding task. Author 1 performed the statistical analyses. Both authors have read this version of the paper and approve its contents. 


\section{References}

Anthony, A., 2004. Gender bias and discrimination in nursing education: Can we change it? Nurse Educator 29, 121-125.

Bartlett, C., Doyal, L., Ebrahim, S., Davey, P., Bachmann, M., Egger, M., Dieppe, P., 2005. The causes and effects of socio-demographic exclusions from clinical trials. Health Technology Assessment 9(38), 1-152.

Buchan, J., 2008. Here to stay? International nurses in the UK. London: Royal College of Nursing. Downloaded January 2, 2008 from http://www.rcn.org.uk.

Buckley, B., Murphy, A., Glynn, L., Hennigan, C., 2007. Selection bias in enrollment to a programme aimed at the secondary prevention of ischaemic heart disease in general practice. International Journal of Clinical Practice 61, 1767-1772.

Cecil, R., Thomson, K., \& Parahoo, K. , 2006. The research assessment exercise in nursing: Learning from the past, looking to the future. Journal of Advanced Nursing 15, 395-402.

Dallas, C., \& Burton, L. (2004). Health disparities among men from racial and ethnic minority populations. Annual Review of Nursing Research 22, 77-100.

Doyal, L., 2001. Sex, gender, and health: The need for a new approach. British Medical Journal 323, 1061-1063.

Evans, J., 2004. Men nurses: A historical and feminist perspective. Journal of Advanced Nursing 47, 321-328.

Fuchs, J., Maschewsky-Schneider, U., 2003. Consideration of gender issues in German-language public health research. Sozial- und Praventivmedizin 48, 227-233.

Geller, S., Adams, M., \& Carnes, M., 2006. Adherence to federal guidelines for reporting of sex and race/ethnicity in clinical trials. Journal of Women’s Health 15, 11231131. 
Hammarström, A., 2003. The integration of gender in medical research and education: Obstacles and possibilities from a Nordic perspective. Women \& Health 37, 121-133.

Holdcroft, A. 2007. Gender bias in research: How does it affect evidence based medicine? Journal of the Royal Society of Medicine 100, 2-3.

Jahn, I., 2005. Taking into consideration gender and sex: New chances to improve the quality of epidemiological and health research. Bundesgesundheitsblatt Gesundheitsforschung Gesundheitsschutz 48, 287-295.

Johnson, S., Karvonen, C., Phelps, C., Nader, S., Sanborn, B., 2003. Assessment of analysis by gender in the Cochrane reviews as related to treatment of cardiovascular disease. Journal of Women's Health 12, 449-457.

LaRosa, J., \& Pinn, V., 1993. Gender bias in biomedical research. Journal of the American Medical Women’s Association 48, 145-151.

Murthy, V., Krumholz, H., \& Gross, C., 2004. Participation in cancer clinical trials: Race-, sex-, and age-based disparities. Journal of the American Medical Association 291, 2720-2726.

Polit, D. F., \& Beck, C. T., 2008. Is there gender bias in nursing research? Research in Nursing \& Health 31, 417-427.

Risberg, G., Hamberg, K., \& Johansson, E., 2006. Gender perspective in medicine: A vital part of medical scientific rationality. BMC Medicine 4, 20-24.

Risman, B. (2004). Gender as social structure: Theory wrestling with action. Gender and Society 18, 429-459.

Ruiz-Cantero, M., Vives-Cases, C., Artazcoz, L., Delgado, A., Calvente, M.G., Miqueo, C., et al., 2007. A framework to analyse gender bias in epidemiological research. Journal of Epidemiology and Community Health 61 Suppl 2, S46-S53. 
Sigma Theta Tau International. Member demographics. Retrieved January 2, 2008, from (http://www.nursingsociety.org/aboutus/ Demographics/Pages/demographics.aspx).

Söderström, M., 2001. Why researchers excluded women from their trial populations. Lakartidningen 98, 1524-1528.

Traynor, M., Rafferty, A., Lewison, G., 2001. Endogenous and exogenous research? Findings from a bibliometric study of UK nursing research. Journal of Advanced Nursing, 34, 212-222.

U. S. Department of Health \& Human Services. Preliminary Findings: 2004 National Sample Survey of Registered Nurses. Retrieved January 2, 2008 from http://bhpr.hrsa.gov/healthworkforce/reports/rnpopulation/preliminaryfindings.htm. U. S. General Accounting Office., 2000. NIH has increased its efforts to include women in research. Washington, DC: GAO (GAO/HEHS-00-96).

Woods, N. F., 1994. The United States women's health research agenda: Analysis and critique. Western Journal of Nursing Research 16, 467-479. 
Table 1

Study Sample, by Country of First Authors’ Institutional Affiliation

\begin{tabular}{|c|c|c|c|c|}
\hline $\begin{array}{l}\text { Country of Lead } \\
\text { Author }\end{array}$ & $\begin{array}{c}\text { Number of } \\
\text { Participants, All } \\
\text { Studies }\end{array}$ & $\begin{array}{l}\text { No. of } \\
\text { Studies }\end{array}$ & \multicolumn{2}{|c|}{$\begin{array}{l}\text { Studies with Information } \\
\text { on Participants' Sex }{ }^{\text {a }} \\
N \quad \%\end{array}$} \\
\hline \multicolumn{5}{|l|}{ Europe } \\
\hline Belgium & 25,255 & 11 & 9 & 81.8 \\
\hline Ireland & 3,312 & 24 & 13 & 54.2 \\
\hline Finland & 5,161 & 14 & 13 & 92.9 \\
\hline Netherlands & 5,238 & 13 & 9 & 69.2 \\
\hline Norway & 811 & 17 & 15 & 88.2 \\
\hline Sweden & 17,399 & 89 & 75 & 84.3 \\
\hline United Kingdom & 22,523 & 170 & 96 & 55.9 \\
\hline Other European* & 90,222 & 30 & 26 & 86.7 \\
\hline \multicolumn{5}{|l|}{ Asia \& Middle East } \\
\hline Hong Kong/China & 6,808 & 56 & 52 & 92.9 \\
\hline Korea & 29,578 & 29 & 27 & 93.1 \\
\hline Taiwan & 18,469 & 79 & 63 & 79.7 \\
\hline Turkey & 4,152 & 16 & 16 & 100.0 \\
\hline Other Asian** & 6,679 & 24 & 20 & 83.3 \\
\hline \multicolumn{5}{|l|}{ Australia/New } \\
\hline Zealand & 13,992 & 72 & 51 & 70.8 \\
\hline \multicolumn{5}{|l|}{ North America } \\
\hline Canada & 58,669 & 68 & 58 & 85.3 \\
\hline United States & 318,519 & 316 & 284 & 89.9 \\
\hline All other countries*** & 1,937 & 13 & 9 & 69.2 \\
\hline TOTAL & 628,724 & 1,041 & 836 & $80.3 \%$ \\
\hline
\end{tabular}

*Includes Denmark, Germany, Greece, Iceland, Italy, Malta, Spain, and Switzerland

**Includes Iran, Israel, Japan, Jordan, Malaysia, and Thailand

***Includes Bermuda, Botswana, Brazil, Colombia, Ghana, Mexico, and South Africa

aCountry differences in percent of studies providing participants' sex information, $\chi^{2}=$ $110.3, p<.001$. 
Table 2

Sex Distribution Information among Participants in Nursing Studies, by Nursing Specialty Area

\begin{tabular}{|c|c|c|c|c|c|c|}
\hline \multirow[t]{2}{*}{$\begin{array}{l}\text { Specialty Area of the } \\
\text { Study }\end{array}$} & \multirow[t]{2}{*}{$\begin{array}{l}\text { Studies: } \\
\quad N\end{array}$} & \multirow{2}{*}{$\begin{array}{c}\text { Studies } \\
\text { with } \\
100 \% \\
\text { female } \\
\text { particips. } \\
N(\%)\end{array}$} & \multirow{2}{*}{$\begin{array}{c}\text { Studies } \\
\text { with } \\
100 \% \\
\text { male } \\
\text { particips. } \\
N(\%)\end{array}$} & \multirow{2}{*}{$\begin{array}{c}\text { Mean } \\
\text { percentage } \\
\text { of female } \\
\text { partici- } \\
\text { pants }\end{array}$} & \multicolumn{2}{|c|}{$\begin{array}{l}\text { 95\% CI for } \\
\text { mean percent- } \\
\text { age female }\end{array}$} \\
\hline & & & & & $\begin{array}{l}\text { Lower } \\
\text { limit }\end{array}$ & $\begin{array}{l}\text { Upper } \\
\text { limit }\end{array}$ \\
\hline \multicolumn{7}{|l|}{ Client Focused } \\
\hline Pediatrics & 77 & 17 (22\%) & $1(1 \%)$ & 65.5 & 59.9 & 71.1 \\
\hline Geriatrics & 130 & $15(12 \%)$ & $2(2 \%)$ & 69.9 & 66.5 & 73.4 \\
\hline Obstetrics/gynecology & 71 & 68 (96\%) & $0(0 \%)$ & 99.1 & 97.9 & 100.0 \\
\hline Oncology & 54 & $16(30 \%)$ & $5(9 \%)$ & 66.7 & 58.2 & 75.2 \\
\hline Cardiopulmonary & 51 & $2(4 \%)$ & $0(0 \%)$ & 46.5 & 40.1 & 53.0 \\
\hline Critical care & 21 & $5(23 \%)$ & $0(0 \%)$ & 59.2 & 46.7 & 71.7 \\
\hline Other medical/surgical & 184 & $24(13 \%)$ & $5(3 \%)$ & 58.6 & 54.9 & 62.2 \\
\hline Psych/mental health & 48 & $13(27 \%)$ & $0(0 \%)$ & 70.9 & 64.0 & 77.7 \\
\hline Community health & 100 & 40 (40\%) & $5(5 \%)$ & 73.5 & 67.7 & 79.3 \\
\hline Health promotion & 52 & 28 (54\%) & $1(2 \%)$ & 81.2 & 73.9 & 88.5 \\
\hline Transcultural & 30 & $13(43 \%)$ & $2(7 \%)$ & 73.5 & 62.4 & 84.5 \\
\hline All client-focused & 639 & 185 (29\%) & 17 (3\%) & 67.6 & 65.4 & 69.7 \\
\hline \multicolumn{7}{|l|}{ Nursing Focused } \\
\hline $\begin{array}{c}\text { Clinical nursing } \\
\text { practice }\end{array}$ & 164 & 32 (20\%) & $2(1 \%)$ & 83.0 & 79.4 & 86.7 \\
\hline Nursing education & 22 & $4(18 \%)$ & $0(0 \%)$ & 84.4 & 78.0 & 90.8 \\
\hline Nursing administration & 18 & $1(6 \%)$ & $0(0 \%)$ & 81.5 & 72.3 & 90.7 \\
\hline All nursing focused & 197 & $36(18 \%)$ & $2(1 \%)$ & 82.9 & 79.7 & 86.0 \\
\hline All studies* & 836 & 217 (26\%) & 17 (2\%) & 71.0 & 69.2 & 72.8 \\
\hline
\end{tabular}


*The numbers in the specialty areas do not add up to the total number of studies because many were coded in two categories. For this reason, tests for differences in percentage female among studies coded in the different specialty areas could not be performed.

Table 3

Mean Percentage Female among Participants in Nursing Studies, by Country of First Author's Institution

\begin{tabular}{|c|c|c|c|c|}
\hline \multirow[t]{2}{*}{$\begin{array}{l}\text { Country of Lead Author's } \\
\text { Institutional Affiliation }\end{array}$} & \multicolumn{2}{|c|}{ All Studies } & \multicolumn{2}{|c|}{$\begin{array}{c}\text { Client-Focused Studies } \\
\text { Only }\end{array}$} \\
\hline & $N$ & $\begin{array}{l}\text { Mean \% of } \\
\text { female } \\
\text { participants }\end{array}$ & $N$ & $\begin{array}{l}\text { Mean \% of } \\
\text { female } \\
\text { participants }\end{array}$ \\
\hline \multicolumn{5}{|l|}{ Europe } \\
\hline Belgium \& Netherlands & 18 & $67.9 *$ & 10 & 61.3 \\
\hline Finland & 13 & $68.7^{*}$ & 8 & -- \\
\hline Ireland & 13 & $78.4 *$ & 6 & -- \\
\hline Norway & 15 & $69.5^{*}$ & 10 & $68.8 *$ \\
\hline Sweden & 76 & $64.8^{*}$ & 60 & $61.9 *$ \\
\hline United Kingdom & 95 & $72.2^{*}$ & 59 & $66.2^{*}$ \\
\hline Other European $^{\mathrm{a}}$ & 26 & $68.3 *$ & 18 & $64.0 *$ \\
\hline \multicolumn{5}{|l|}{ Asia \& Middle East } \\
\hline Hong Kong/China & 52 & $59.9 *$ & 46 & 56.3 \\
\hline Korea & 27 & $67.8 *$ & 27 & $66.5 *$ \\
\hline Taiwan & 63 & $65.5 *$ & 55 & $63.2 *$ \\
\hline Turkey & 16 & 59.4 & 14 & 60.2 \\
\hline $\begin{array}{c}\text { Other Asian/Middle } \\
\text { Eastern }^{\mathrm{b}}\end{array}$ & 20 & $75.0 *$ & 12 & $74.3 *$ \\
\hline Australia/New Zealand & 51 & $70.8^{*}$ & 29 & $63.1^{*}$ \\
\hline \multicolumn{5}{|l|}{ North America } \\
\hline Canada & 58 & $78.3 *$ & 40 & $75.6 *$ \\
\hline United States & 284 & $74.9 *$ & 238 & $72.7^{*}$ \\
\hline Total** & 836 & $71.0 *$ & 639 & $67.6 *$ \\
\hline
\end{tabular}

${ }^{\mathrm{a}}$ Includes Denmark, Germany, Greece, Iceland, Italy, Malta, Spain, and Switzerland b Includes Iran, Israel, Japan, Jordan, Malaysia, and Thailand

*Lower limit of the $95 \%$ CI for this group of studies is greater than $50.0 \%$ female. 
**Differences among countries in mean percentage female was significant, for all studies $(F=2.42, d f=14,821, p=.002)$ and for client-focused studies $(F=2.22, d f=14,624, p$ $=.006$

Table 4

Mean Percentage Female among Participants in Client-Focused Nursing Studies, by Authors' Sex

\begin{tabular}{|l|c|c|c|c|}
\hline $\begin{array}{l}\text { Sex of First Author and Authorship } \\
\text { Team }\end{array}$ & $\begin{array}{c}N: \\
\text { Studies }\end{array}$ & $\begin{array}{c}\text { Mean percent- } \\
\text { age of female } \\
\text { participants }\end{array}$ & \multicolumn{2}{|c|}{$\begin{array}{c}\text { 95\% CI, mean } \\
\text { percentage female }\end{array}$} \\
\cline { 4 - 5 } & & & $\begin{array}{c}\text { Lower } \\
\text { limit }\end{array}$ & $\begin{array}{c}\text { Upper } \\
\text { limit }\end{array}$ \\
\hline Sex of first author & & & & \\
Female & 539 & 70.0 & 67.7 & 72.2 \\
Male & 74 & 52.1 & 45.3 & 58.9 \\
& & & & \\
\hline Sex configuration of team & & & \\
Only 1 author, female & 84 & 78.2 & 72.5 & 83.9 \\
Only 1 author, male & 6 & 39.6 & 1.7 & 77.4 \\
Multiple authors, all female & 207 & 70.2 & 66.6 & 73.9 \\
Multiple authors, at least 1 male & 262 & 62.9 & 59.0 & 65.8 \\
& & & & \\
\hline
\end{tabular}

${ }^{\mathrm{a}}$ Differences between male and female first authors in mean percentage female among their study participants were significant $(t=5.35, d f=612, p<.001)$

${ }^{\mathrm{b}}$ Differences between the four author configuration groups in mean percentage female among their study participants were significant $(F=9.60, d f=3,555, p<.001)$ 